\title{
LA FLORACION DE LOS MATORRALES, UN RECURSO NATURAL DE SIERRA MORENA
}

Domingo A VILA FERNANDEZ *

En los últimos años estamos asistiendo en Andalucía a un proceso de cocienciación y reflexión sobre nuestra realidad económica, promovido fundamentalmente desde los intelectuales y los políticos, que potencia una doble consideración: el reconocimiento, por una parte, de nuestra débil situación económica en el contexto nacional, con referencias constantes al subdesarrollo y dependencia regional de Andalucía, y la búsqueda y manifestación, por otra, de la variedad y riqueza de nuestros recursos naturales, infraaprovechados unas veces, explotados por foráneos otras.

En este contexto quiere insertarse esta breve reflexión basándonos para ello en el estudio somero del aprovechamiento apícola de las floraciones del matorral en Sierra Morena, utilizando como área de observación el espacio occidental de la misma, que constituye la franja Norte de la Provincia de Huelva: algo más de 300.000 hectáreas, de las que 252.258 son terreno forestal y dentro de éste, casi el 22 por ciento aparece ocupado por matorrales (RUB!O, 1981; AVILA, 1981).

\section{LAS VARIEDADES DEL MATORRAL}

Como consecuencia de la destrucción, más o menos lejana, de grandes extensiones del bosque primitivo, encontramos actualmente en Sierra Morena dos tipos de formaciones que se corresponden con dos etapas de sucesiones de la vegetación originaria: las zonas arbustivas altas y los matorrales. Estas formaciones de sucesión no se deben tanto a etapas regresivas cuanto progresivas del bosque primitivo (CEBALLOS, 1945), puesto que se

* Profesor Titular de Geografía. Universidad de Sevilla. 
trata de la recuperación vegetacional de un bosque que fue totalmente destruído de forma sincrónica por el hombre en función de dos tipos de aprovechamiento: cultivos cerealistas, a base de rozas, y carboneo. Por ello, estas formaciones aparecen ocupando dos tipos de zonas totalmente distintas descle el punto de vista topográfico:

- Zonas levemente onduladas, de pendientes suaves, donde cupo la posibilidad de cultivos cerealistas, $y$

- Zonas escarpadas, de fuertes pendientes y dificilmente accesibles. Fueron éstas las áreas utilizadas preferentemente para el carboneo y, puesto que la destrucción no fue completa, las sucesiones se encuentran en estadios de recuperación más avanzados.

Estas formaciones determinan la aparición de diversas asociaciones vegetales desperdigadas por el ámbito de Sierra Morena, de las que destacamos las siguientes:

1. Asparago-Rhamnetum Oleoides. Esta asociación, de carácter casi arbóreo, representa la primera etapa de sustitución de la Oleo-Quercetum rotundifoliae. Como especies características de la misma aparecen la coscoja (Quercus coccifera), el torbisco (Daphne gnidium), el lentisco o charneca (Pistacia lentiscus), y el romero (Rosmarinus officinalis). De todas ellas la de mayor importancia de cara al aprovechamiento apícola es el romero, con floraciones esporádicas muy dilatadas en el tiempo y de gran calidad tanto para la producción de pólen como de miel. Ofrece esta especie de nuestras sierras una cualidad fundamental para la apicultura; se trata de su temprana floración coincidente con las primeras lluvias otoñales, que tras la escasez del período estival permite a los enjambres aprovisionarse de cara a la estación invernal.

2. Phillyreo-Arbutetum. Sobre los sustratos silíceos aparecen estos madroñales, propios de clima mediterráneo húmedo. Viene caracterizada esta asociación por especies como el madroño (Arbutus unedo), dominante en ella y que le da nombre, la lentisca o lentisco blanco (Phillyrea angustifolia), el mirto o murtera (Myrtus communis), el brezo blanco gigante (Erica arborea) y la jara cervuna (Cistus populifolius), entre otras especies menos comunes. Todas ellas son de enorme valor para el apicultor por su variada e intensa floración que además tiene la ventaja de mantenerse hasta bien entrado el verano por su situación en las umbrías y canales de arroyada más húmedas.

3. Quercetum Fruticosae. Asociación de apretado matorral de poca altura en que se encuentran, junto a brotes de cepa del encinar, diversas especies del matorral más xerófilo. Sus floraciones son fugaces y poco valiosas de cara al aprovechamiento apícola. 
4. Ulici-Cistetum Ladaniferi. En esta asociación de matorral se incluyen la mayor parte de los jarales, siendo característica común de sus distintas variaciones la presencia de la jara pringosa (Cistus ladanifer) y la aulaga (Ulex parviflorus), junto a las lavandas (Lavandula stoechas y Lavandula pedunculata). La floración de esta asociación, que se produce entre los meses de Marzo y Abril, tiene un enorme valor para la moderna apicultura. En efecto, es la más apreciada por la enorme cantidad de pólen que proporcionan todas sus especies, sobre todo las jaras. Es justamente la floración de estas asociaciones la que atrae en Primavera hacia Sierra Morena a una gran cantidad de apicultores foráneos que llegan exclusivamente a la captación del pólen.

5. Lavandulo-Cistetum Albidi. Aparece asentada en las bandas cálidas y se caracteriza por sustituir a la jara pringosa por otra de menor porte (Cistus albidus) aunque también de floración abundante y muy polinífera.

6. Ulici-Ericetum Umbellatae. Se trata de los brezales, que suponen una nueva etapa de regresión con respecto a los madroñales. Su floración, muy intensa, tiene gran valor para los apicultores por dos razones: por su abundancia y sobre todo por lo temprano de su aparición puesto que dominan diversas especies de brezos (Erica umbellata, Erica australis y Erica scoparia) que están en plena floración ya en los últimos meses del invierno.

Junto a estas asociaciones, otras de menor importancia completan el panorama de los matorrales de Sierra Morena. Su importancia para la apicultura reside, junto a la intensidad de su floración y la riqueza en pólen de algunas de sus especies, en el hecho de que aparecen floridas prácticamente a lo largo de todo el año (abre el ciclo la floración del romero con las primeras lluvias otoñales para cerrarse bien avanzado el verano con mirtos y madroños) aunque con mayor abundancia en primavera, sobre todo por lo que a las especies más poliníferas se refiere.

\section{SU PAPEL EN LA ECONOMIA TRADICIONAL}

No han sido, ciertamente, espacios despreciados en la economía tradicional de Sierra Morena estas formaciones vegetales a que aludimos. Sin embargo, como espacios marginales, han soportado una actividad económica de tipo marginal y complementario, tanto para la economía familiar de autoabastecimiento como para la economía de mercado de las explotaciones mayores. Estas actividades se pueden resumir en: 
--. El carboneo: los jarales sirvieron como base a un carboneo de segunda fila, las cisqueras, que sin embargo fue fundamental para la subsistencia de las economías más débiles.

-- Las rozas: aparece así la figura del pegujalero, jornalero que roza el matorral y lo aprovecha para sementera el primer año, devolviéndolo limpio al propietario, que pastorea los rastrojos (FOURNEAU y ROUX, 1974).

- El pastoreo con ganado caprino. Ha sido siempre, y sigue siendo, la principal actividad económica con sede en el matorral, encontrándose actualmente en auge por el valor alcanzado en las últimas campañas por la carne de cabrito. Siendo éste el tipo de ganadería más extensiva de cuantas modalidades aparecen en la península, supone sin embargo la forma más intensiva de aprovechamiento de estos espacios marginales.

- Las colmenas. Siempre han aparecido en el límite del matorral aunque casi nunca con valor comercial sino más bien como actividad complementaria en las economías de autoabastecimiento, a pesar de que es muy vahioso el potencial de estos matorrales de cara al aprovechamiento apícola.

\section{NUEVAS ORIENTACIONES}

Dado el carácter marginal de estos aprovechamientos tradicionales, su productividad era prácticamente nula si exceptuamos el caso del pastoreo, aunque incluso en él, el rendimiento económico por hectárea resultaba mínimo. No es de extrañar por tanto que comiencen a aparecer nuevas orientaciones en la actividad económica con sede en el matorral.

De esta forma, en las últimas décadas aparece una actividad semiartesanal: la destilación de esencias de jaras. No se ha generalizado este tipo de aprovechamiento que se mantiene tan sólo como reducto en algunos pueblos del Andévalo Occidental.

Lo que sí adquirió un enorme auge fue la actividad repobladora a base de eucaliptales que en la provincia de Huelva ha llegado a sustituir por éste tipo de aprovechamiento forestal más de 200.000 hectáreas ocupadas anteriormente por matorrales (MARQUEZ, 1977).

En este contexto de búsqueda de una mayor productividad en el aprovechamiento de estos espacios marginales, surge la intensificación de la apicultura. Sin embargo, aunque ha sido ésta una actividad tradicional en Sierra Morena, su intensificación y modernización encuentra su explicación con la llegada de apicultores foráneos. 


\section{LA LLEGADA DE APICULTORES VALENCIANOS}

Es vieja la tradición apícola en el Levante español. Y no es de extrañar, puesto que tan sólo en la floración del azahar (aproximadamente mes y medio) se pueden alcanzar producciones medias que superan los 20 kilogramos de miel por colmena, siendo además la miel blanca del azahar muy apreciada y cotizada, a la vez que de fácil comercialización.

Pero lo reducido en el tiempo de la campaña del azahar, lleva pronto a los apicultores valencianos a emigrar anualmente con sus colmenas melíferas en un recorrido que les lleva desde los azahares del Levante a las Serranías de Cuenca, Teruel y Guadalajara para la floración del romero (Mayo). De allí al Sistema Central para aprovechar tomillos, cantuesos y brezos (Junio), para finalizar su campaña melífera en la floración de los girasoles sevillanos y gaditanos, y descubrir en el viaje el potencial de nuestros jarales.

De esta forma, cuando en los primeros años de la década de los setenta comienza a demandarse, no tanto miel cuanto pólen, con destino a los mercados centroeuropeos, y con un fuerte alza en los precios, comienzan a fluir hacia nuestras Sierras gran cantidad de colmeneros en busca de la floración de sus matorrales, ricos en pólen.

Aunque es difícil una evaluación exacta de los efectivos que recorren nuestros montes, puesto que sus cartillas ganaderas están censadas en sus lugares de origen, hemos detectado en la Sierra de Huelva la presencia en la última campaña de más de cien colmenares, casi todo ellos de apicultores valencianos. Ello supone que anualmente más de 30.000 colmenas se asientan solamente en la Sierra Morena onubense durante los meses de Marzo a Junio, para de allí emigrar en busca de la floración de los girasoles campiñeses.

\section{UN PRODUCTO QUE SE VA DE ANDALUCIA}

Un cálculo fugaz basado en las posibilidades de un año medio nos puede llevar a la conclusión de que sólo estas treinta mil colmenas sacan de Andalucía anualmente una producción bruta que podemos valorar a la baja en casi cien millones de pesetas.

En efecto, durante los meses de primavera, las floraciones del matorral, pero fundamentalmente los jarales, permiten recoger aproximadamente seis kilogramos de pólen por colmena. Ello supone contabilizar un total de 180.000 kilogramos de pólen, cuyo precio al exportador se situó en la última campaña en torno a las 300 pesetas por kilogramo (en campañas anteriores se llegó a cotizar a 500 ptas. kilogramo), es decir, unos 54 millones de pesetas en conjunto. Junto a ello, y durante la campaña del girasol, cada colmena puede conseguir una producción media de 10-12 kilogramos de miel, o sea, 
un total de 300.000 kilogramos, valorados en aproximadamente $45.000 .00 \mathrm{C}$ de pesetas.

En definitiva, ello supondría para una comarca como la Sierra de Huelva. cuyo espacio rural tiene un producto bruto global de 2.671 millones de pesetas (AVILA, 1981) un aumento anual del mismo superior al 3,5 por ciento. Y ello justamente, en una de las comarcas deprimidas de Andalucía.

Como investigadores, esta situación tan sólo hasta ahora entrevista como realidad en nuestros trabajos de campo y de la que damos noticia, nos ha su. puesto un reto de estudio que ya cuaja en la realización de una tesis de licen. ciatura sobre la apicultura en la Provincia de Huelva.

\section{BIBLIOGRAFIA CITADA}

AVILA FERNANDEZ, D.: Ocupación, usos y organización del espacio productivo en la Sierra de Huelva, Dept. de Geografra, Sevilla, 1981. Tesis doctoral.

CEBALLOS Y FERNANDEZ DE CORDOBA, L.: Los matorrales españoles y su significación. Discurso de ingreso en la Real Academia de C.E.F.y N. Madrid, 1945.

FOURNEAU, F. y ROUX, B.: Vie rurale et crise agraire dans la Sierra de Aracena. Mélanges de la Casa de Velázquez, T. X, París, 1974.

MARQUEZ FERNANDEZ, D.: La geoeconomía forestal de Huelva y el dilema de sus eucaliptales. Inst. de Desarrollo Regional. Universidad de Sevilla, 1977.

RUBIO RECIO, J.M.: "Paisajes vegetales de Sierra Morena Occidental y su utilización" en GADES, Rev, del C.U. de Cádiz, 1981, pp. 179-185. 